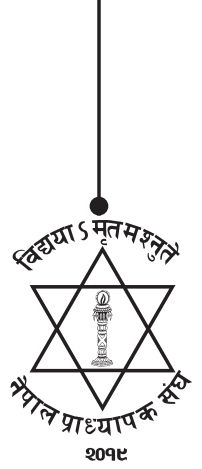

NJ: NUTA

\title{
Productivity and Responsiveness of Tax Yields in Nepal
}

\author{
Bashu Dev Dhungel \\ Lecturer, Tribhuvan University \\ Email for correspondence: dhungelbd@yahool.com
}

\begin{abstract}
This study is based on secondary data published by the government of Nepal covering a period between 1990/91 and 2013/14 fiscal year. The various sources of revenue as a proportion of the GDP have been analyzed during this period. An adjusted revenue series have been prepared for total and the individual taxes by using the Sahota method of proportional adjustment. The Productivity and Responsiveness of taxes has been measured by estimating the elasticity and buoyancy co-efficient using double log linear regression equation. The findings reveal that indirect tax has been playing a dominant role for total tax revenue collection. Indirect tax is considered regressive in nature and is not justifiable on equity ground and progressiveness. Regarding elasticity and buoyancy, the elasticity coefficient of overall taxes are less than unity and it is inelastic in nature. But, buoyancy coefficient of overall taxes is greater than unity. This high buoyancy but low elasticity of all major tax heads signifies the need for additional government efforts of expanding the tax base to increase revenue and lower its resource gap.
\end{abstract}

Key words: Elasticity and buoyancy, productivity and responsiveness.

\section{Introduction}

The major challenge to Nepalese tax system is how to accelerate tax effort ratio to the maximum for meeting minimum requirements for development. Nepal's tax system is circumscribed by serious structural constraints. The major constraints existing in the tax system is lack of simplicity and transparency. Despite these in Nepal, we find the problems of an extremely limited tax base, low tax elasticity, poor voluntary compliance, less effective tax administration, growing arbitration in assessment, rigid and incomprehensive tax laws and regulations, numerous tax shelters and taxation in Nepal has so far been attributed to "negotiation" resulting in rampant corruption.

Tax evasion and leakages are other problem of the Nepalese tax system. The existing situation of tax leakages in Nepal is very alarming. The estimated evasion is more than 40 percent of taxable capacity (Ghimire, 2006). The annual average growth rate of income tax collection was about 20 percent before enforcement of the new Income Tax Act. The annual average growth rate has declined in about 10 percent. Similarly, the trend of growth average amount of tax paid by each taxpayer has reduced while the annual growth of tax registrants is around 25 percent. This scenario shows four types of non- compliance. First non-registration, second non-filling, third delayed filing and the fourth is under reporting of income /sales/production/import. Poor tax administration is often pronounced as the major challenge to a good tax system in Nepal. Poor tax administration imposes additional burden and uncertainties. Uncertainty is heightened by increasing resource to taxation through flat charges without direct regard to the profitability of investment. From a taxation standpoint, the foreign investor may not 
feel that there is a welcoming environment. There is tendency of providing tax rebate and exemption by reforming sectorial laws and cabinet decision. Tax personnel do not exhibit taxpayer-friendly behavior, and lack of advance information technology that is compatible with international standards. These are some of the problems in tax administration. These problems are increasing tax collection expenditure and tendency of the evasion as well.

For the last many years Nepal is facing acute shortage of resources resulting in increasing budgetary deficits. As a result, dependence on external as well as internal borrowings has inordinately been increased in the budgetary structure of Nepal. This situation is likely to continue in future. Therefore, there is a great challenge for developing appropriate strategy for taxation ensuring effective resource mobilization for reducing acute resource gap. If resource mobilization is the function of economic development, it is essential to neutralize the vulnerabilities facing tax structure that would help narrow down the existing resource gap. The successful tax system is that in which resource mobilization could be emphasized without creating additional tax burden to the taxpayers. Interventionist approach to resource mobilization suggests for maximizing revenue through increasing tax rates and legal base, which is obsolete in recent years. Currently, reductionist approach is under consideration to resource mobilization that refers to lowering down of tax rates in many developing countries (Dahal, 2004).

Thus, resource mobilization will be justified only when there would be no increase in the tax rates and legal base. Internal resources are mobilized by improving efficiency of tax administration. This requires identifying the potential range of taxation and expenditure that would be apparatus to reduce the resource gap. Trends in external and internal borrowings must be examined to understand the overall impacts of resource mobilization on narrowing down the resource gap.

\section{Research Objective}

- To examine the productivity and responsiveness of tax yields of Nepal by estimating elasticity and buoyancy coefficient.

\section{Review of Literature}

Goode (1984), in his publication "Government Finance in Developing Counties" emphasized that, tax is the compulsory contribution to the government and made without reference to a particular benefit received by the tax payer. The relation between taxation and economic development has long been a matter of concern to policy makers and students of public policy alike. The stability of economy also becomes an important subject of analysis. Subsequently, the range of concern tax widens to include the effect of taxation not just on the rate of growth of national income but also on the distribution of that income by income size, class employment, and other objective of policy.

Dahal (1983), in his study "Taxation in Nepal: A study of its Structure, Productivity and Burden" says that, the term 'elasticity' is also called 'built-in flexibility' or stabilized coefficient. It indicates that the size one or the magnitude of a tax would have been over the period of time when there would be no change in the tax rates and the legal bases. 'Elasticity' provides the basis for the natural growth of the revenue to the national income (GDP or GNP) without any change in the rate structure and the bases. Thus, it provides real or stabilized value of taxes. On the contrary, buoyancy estimates what actually happens. Buoyancy provides a floating value or face value of taxes which includes both automatic growth and the discretionary changes. It reflects the influences of such factors as sensitivity of the tax base to the growth in national income, the progressivism of the rate structure, the nature and 
frequency of discretionary actions and the change in prices. Thus, it can be viewed as a total account of the tax responsiveness to the changes in the national income.

Adhikari (1995) has studied the "Tax elasticity and Buoyancy in Nepal" during the period from 1974/75 to 1993/94, further this whole sample period was divided into two sub period (i) from $1974 / 75$ to $1983 / 84$ and (ii) $1984 / 85$ to $1993 / 94$, and using Sahota method for data adjustment. He found the elasticity coefficient of total revenue, income tax; tax on consumption, and import duties was $0.65,0.39,0.73$ and 0.51 respectively. The elasticity coefficient of total revenue, income tax, tax on consumption, and import duties was in period (i) $0.40,0.34,0.83$ and 0.46 and in period (ii) $0.68,0.54$, 1.21 and 0.40 respectively. At the same time the buoyancy coefficient of total revenue, income tax, tax on consumption, and import duties of the whole period was 1.10, 1.14, 1.06, and 1.05 respectively. The buoyancy coefficient of total revenue, income tax, tax on consumption, and import duties was in period (i) $1.06,1.07,1.61$, and 3.90 and in period (ii) $1.05,1.07,1.30$, and 0.92 respectively.

Dahal (2000), in his study "Measuring the Responsiveness and Productivity of Tax Yields" explain the two popular concepts frequently used by researcher and academicians in measuring the responsiveness and the productivity of taxes in a tax system are the concept of 'Elasticity and Buoyancy'. The tax elasticity and the buoyancy of a tax system are commonly known as automatic stabilizers. If a tax system is elastic (i.e the value of elasticity is more than or equal to one) then the tax system is called stabilized and there is no need of any corrective action by any external authority for the smooth functioning of the tax system.

Dahal (2009), published an article about "Taxation in Nepal: Structure, Issue and Reforms". The objective of the study was to examine current structure of taxation with the international compare and identify the major issues and problems taxation. The data were collected from Economic Survey (MOF), and Budget Speech. The OLS method was used for data analysis. In developing countries resource gap is critical and widening resulting to huge fiscal and budgetary deficit.

The growing resource gap is frequently off-set by mobilizing internal and external borrowing and consequently shifts the burden of debt to prosperity. Therefore, revenue mobilization is challenging proposition in developing economies where a majority of the people live in abject poverty and the people engaged in economic activities have extremely limited taxable capacity. In addition, legal base of taxation is compressed with unlimited tax shelters and tax administration lacks innovation mechanism to identify new tax payers and bring them into tax-net. In developing economies illegal economic activities have greatly increased over the years resulting to poor voluntary compliance due to indifference attitude of the taxpayers toward government spending. Thus, interface between diminishing efficiency of tax administration and delinquency on the taxpayers is becoming critical.

\section{Research Methodology}

Taxes for the purpose of present study are taken to mean any compulsory payment without any direct quid-pro quo. Accordingly, revenue sources of government of Nepal, as are shown under the heading of custom duties, excise duties, import duties, sales tax (VAT: under the sales tax or VAT, contract tax, Air flight tax, hotel tax, entertainment tax has been taken and before 1997 VAT is called sales and after VAT itself) which was considered as indirect tax. Whereas income tax, registration tax are taken as direct taxes. Remaining sources of revenue like fees, dividend, and penalty, fine are considered as non-tax revenue. To attain the objective of this study consider different categories of 
revenue heading including tax revenue and non-tax revenue. The different single tax heads are taken as dependent variable which are regressed with a single independent variable GDP (Gross Domestic Product) and their component while estimate elasticity and buoyancy coefficient.

\section{Nature and Source of Data}

Most of the data used in this study are secondary data published in various issue of "Budget Speech" and, "Economic Survey". The other sources of data are various publications of CBS, NRB and WB reports .This study is based on the time series data for the Nepalese Economy from 1990/91 to $2013 / 14$.

\section{Measurement of Responsiveness of Taxes}

In order to estimate elasticity and buoyancy accurately, it is necessary to separate discretionary changes from the tax revenue series. Experts have used several methods to separate automatic and discretionary changes in tax revenue systems. There are various methods like, Constant Structure Method, Divisia Index, Dummy Variable Method and Proportional Adjustment Method. Among the four methods, Proportional adjustment method is relevant in underdeveloped countries where data arrangements are not good. Within this method, there exist several alternative methods and the following are more important: Prest method; Sahota method; and Chand and Chelliah method. If interpreted the data in a correct manner, all these three methods (prest, sahota, and chand and chelliah) yielded the same adjusted revenue series. Therefore, Sahota method has been used to calculate the adjusted revenue series.

Sahota Method (1961), Sahota and Prest Methods appear to be quite different they yield the same estimation of income elasticity. Sahota has used a comprehensive proportional adjustment method to separate the discretionary change of revenue from total growth of revenue. In this method, the percentage contribution of next tax proposal to the total estimated revenue has been taken in the same proportion to calculate discretionary change from actual collection of total revenue. For example, if a new tax proposal is estimated as 10 percent of the total estimated revenue, the same proportion of 10 percent will be deducted from or added to the actual tax receipts to make the revenue series adjusted and cleared by eliminating the effect of discretionary changes.

$$
I T_{t}=\frac{A T_{t} \pm R T_{t}}{A T_{t^{-1}}} \times I T^{t^{-1}}
$$

Symbolically,

Where,

$\mathrm{IT}_{\mathrm{t}}=$ Adjusted or net tax yield at time $\mathrm{t}$,

$\mathrm{AT}_{\mathrm{t}}=$ Actual tax yield at time $\mathrm{t}$,

$\mathrm{AT}_{\mathrm{t}-1}=$ Actual tax yield at time $(\mathrm{t}-1)$

$\mathrm{RT}_{\mathrm{t}}=$ Actual discretionary change at time $\mathrm{t}$

$\mathrm{IT}_{\mathrm{t}-1}=$ Adjusted or net tax yield of previous year ( $\left.\mathrm{t}-1\right)$

The model specified in this study comprises of several equations to examine the responsiveness and productivity of Nepalese tax system. But single regression analysis is used to estimate buoyancy and elasticity coefficients of various revenue series. Moreover, regression equations are transformed to double log linear to have the estimate of elasticity and buoyancy of various specified relation. 
Furthermore, in order to examine the structural change before and after the structural adjustment programmed in 1990, the double log linear models are used in the study.

To estimate the elasticity and buoyancy of various individual taxes the following regression equation are used:

$\ln \mathrm{T}=\alpha+\beta \ln \mathrm{Y}+\mu$

$\ln \mathrm{T}_{\mathrm{n}}=\alpha+\beta_{1} \ln \mathrm{Y}+\mu_{1}$

Where,

$\ln \mathrm{T}=$ Adjusted tax revenue

$\ln \mathrm{T}_{\mathrm{n}}=$ Actual tax revenue

$\mathrm{Y}=$ Gross domestic product

$\mu \& \mu_{1}=$ Stochastic Variable

1n =Natural Log,

$\beta=$ Elasticity coefficient

$\beta_{1}=$ Buoyancy coefficient

\section{Statistical Tests}

In order to arrive at valid conclusion, different statistical tools are performed. Since the analysis is based on the time series data, following particular tests are carried out.

\section{$\mathbf{R}^{2}$ and Adjusted $\mathbf{R}^{2}$ estimation}

The degree of relationship existing between dependent and independent variables is shown by the coefficient of determination $\left(\mathrm{R}^{2}\right)$. Hence, in each case, the coefficient of determination $\left(\mathrm{R}^{2}\right)$ has been calculated in order to test the explanatory power of independent variables.

$R^{2}=1-\frac{\sum e^{2}}{\sum y^{2}}=\frac{\hat{a}_{i} \sum y x_{i}}{\sum y^{2}}=\frac{\hat{a}_{1} \sum y x_{1}+\hat{a}_{2} \sum y x_{2}+\ldots \ldots+a_{k} \sum y x_{k}}{\sum y^{2}}$

Where, $y=Y-\bar{Y}, x=X-\bar{X}$

Similarly, Adjusted $\left(\mathrm{R}^{2}\right)$ is calculated by following formula. It is denoted by $\bar{R}^{2}$.

i.e. $\bar{R}^{2}=1-\frac{\sum e^{2} / n-k}{\sum y^{2} / n-1}$

Where,

$\mathrm{n}=$ total number of observation.

$\mathrm{k}=$ number of parameter.

\section{T-Test}

The small sample test, t-test, is performed in order to identify the statistical significance of an observed - $^{-m p l e}$ regression coefficient and the formula for calculating the value is:

$\mathrm{t}=\hat{\mathrm{a}}_{\mathrm{i}} / \mathrm{SEa}_{\mathrm{i}}$

Where, $\hat{\mathrm{a}}_{\mathrm{i}=}$ estimated value of $\mathrm{a}_{\mathrm{i}}$,

S.E. $\left(\hat{a}_{\mathrm{i}}\right)_{=}$standard error of $\hat{a}_{\mathrm{i}}$ or $\sqrt{\operatorname{Var} \hat{a} \mathrm{i}}$ 


\section{F-test}

F-test is used for measuring the overall significance of the estimated regression, which is also a test of significance of $\mathrm{R}^{2}$ because these two vary directly. When $\mathrm{R}^{2}=0, \mathrm{~F}$ is zero and when $\mathrm{R}^{2}=$ $1, \mathrm{~F}$ is infinite. That is to say, larger the $\mathrm{R}^{2}$, the greater the $\mathrm{F}$ value. Thus, large value of F-test implies that the overall significance of the estimated regression is good. The $\mathrm{F}$ value can be computed as:

$$
\mathrm{F}=\mathrm{R} 2 / \mathrm{k}-11-\mathrm{R} 2 / \mathrm{n}-\mathrm{k}
$$

Where,

$\mathrm{k}=$ Total number of parameters to be estimated.

$\mathrm{n}=$ number of observation

$\mathrm{R}^{2}=$ coefficient of determination.

\section{Auto correlation (Durbin Watson Test)}

Auto correlation is a statistical test that determines whether a random number generator is producing independent random numbers in a sequence. The Durbin-Watson test is a widely used method of testing for auto correlation. This statistic can be used to test for first-order auto correlation. The DW test is used to detect the presence or absence of auto correlation.

$\mathrm{D} . \mathrm{W}=\sum_{i=2}^{t}\left(e_{i}-e_{i-1}\right)^{2} / \sum_{i=1}^{t} e_{i}^{2}$

Where, $\mathrm{e}=$ the estimate error

To determine the critical DW value, the degrees of freedom is used ' $k$ ' and ' $n$ '. Where, $k$ ' is the number of explanatory variables and n' is the number of observation. So, computed and critical DW values are compared to see if there existed auto correlation.

\section{Structure of Taxation}

In the context of tax structure the contribution of total tax revenue to total revenue is around 80 percent and remaining 20 percent of revenue collected from non-tax revenue over the study period. In the context total tax revenue, indirect taxes play a prominent role in the revenue mobilization. The contribution of indirect tax to total tax revenue is 70.74 percent and remaining 29.26 percent tax revenue collected from direct tax. The indirect tax is considered as regressive in nature, but we are depending upon regressive taxation system.

In the decade of 1970s, custom duties were the major of source of indirect tax revenue. After the implementation of broad-base tax system VAT in 1997, the major source of the tax revenue is VAT. In present, VAT is the first position in total tax revenue collection to compare the other tax heads. In the FY 2013/14 the contribution of VAT is 49.76 percent to total indirect tax revenue collection. In the context of direct tax, the contribution of income tax has continuously increasing and reached to around 71 percent in FY 2013/14 to direct tax revenue collection. The implementation of broad-base value added tax in 1997 and income tax that gives quite satisfactory performance in the revenue mobilization. However, this improvement is not at all substantial enough to address the issue of increasing fiscal imbalance in the country.

\section{Productivity and Responsiveness of Taxation}

The study found that, the elasticity coefficient of all tax heads under consideration are less than unity. However, buoyancy coefficient for major tax heads and individual tax heads are greater 
than unity. This low elasticity and high buoyancy for total revenue as well as individual taxes indicate that the government has concentrated more on introducing various discretionary measures, rather than broadening the tax bases. The increasing trend of discretionary effect to draw government revenue indicates additional efforts of government in tax structure. The higher discretionary effect signifies more burdens to the taxpayers, which is not suitable on the ground of equity and progressiveness. This high buoyancy but low elasticity of all major tax and non tax revenue heads signifies the additional government efforts of changing the base and the rate structure to increase revenue.

Table 1. Elasticity Coefficient ( $\beta$ ) for Study Period

\begin{tabular}{lcccccc}
\hline Tax Heads & Coefficients $(\boldsymbol{\beta})$ & $\mathbf{R}^{2}$ & $\mathbf{A d j} . \mathbf{R}^{2}$ & $\mathbf{T}$ & $\mathbf{F}$ & DW \\
\hline Total Revenue & $0.60(0.070)^{*}$ & 0.99 & 0.99 & 8.65 & 3088.31 & 1.23 \\
Total Tax Revenue & $0.64(0.085)^{*}$ & 0.99 & 0.99 & 7.54 & 2002.09 & 1.34 \\
Non-Tax Revenue & $0.47(0.036)^{*}$ & 0.89 & 0.88 & 12.97 & 147.78 & 1.93 \\
Direct Tax & $0.62(0.108)^{*}$ & 0.97 & 0.97 & 5.68 & 679.62 & 1.76 \\
Indirect Tax & $0.64(0.080)^{*}$ & 0.99 & 0.99 & 7.94 & 236.14 & 1.40 \\
Income Tax & $0.74(0.135)^{*}$ & 0.95 & 0.95 & 5.43 & 383.74 & 1.55 \\
Sales Tax/VAT & $0.69(0.124)$ & 0.97 & 0.97 & 5.58 & 764.12 & 0.94 \\
Custom Duties & $0.69(0.042)^{*}$ & 0.97 & 0.97 & 16.40 & 775.56 & 1.64 \\
Excise Duties & $0.42(0.076)^{*}$ & 0.97 & 0.97 & 5.51 & 677.5 & 1.99 \\
\hline
\end{tabular}

(Authors own calculate based on Economic Survey Data).

Note: *values with in parenthesis are the standard errors of the parameters.

During the study period elasticity coefficient of total revenue is found to be 0.60 with best theoretical fit of the estimated parameter at 1 percent significance level. Since the coefficient is less than unity, total revenue cannot be considered to be elastic with respect to the change in GDP. Adjusted R squared value is 0.99 which clarifies that 99 percent change in total revenue is explained by the change in GDP. Total tax revenue has an elasticity coefficient of 0.64 showing that 100 percent increase in GDP has contributed to a 64 percent increase in total tax revenue collection during the period. R squared and adjusted $\mathrm{R}$ squared is found to have value of 0.99 . F and $\mathrm{T}$ statistics support the statistically significant fit of the model. Non-tax revenue has an elasticity coefficient 0.47 . Adjusted $\mathrm{R}$ squared value is 0.88 implying that 88 percent variation in non-tax revenue is explained by the change in explanatory variable GDP. The model is significant at 1 percent.

Total direct tax is found to have an elasticity coefficient of 0.62 explaining that 100 percent increase in GDP during the period under analysis has contributed to a 62 percent increase in total direct tax. The relationship between explained and explanatory variable is satisfactorily maintained and the estimated parameter is statistically significant at 1 percent. DW statistics is found to 1.76 , implies that there is no auto correlation among the disturbance terms. Income tax has registered an elasticity coefficient of 0.74 implying that a 100 percent increase in GDP has contributed to a 74 percent increase in income tax. Adjusted R squared value is 0.95 showing 95 percent change in total income tax, which is explained by the change in GDP and the rest 5 percent variation due to other 
factors. $\mathrm{F}$ and $\mathrm{T}$ statistics show best theoretical fit of the estimated parameter at 1 percent significance level. DW statistics is at 1.55 , implies that there is no auto correlation in the model.

Total indirect tax is found to have an elasticity coefficient of 0.64 implying that one percent change in explanatory variable has caused on an average 0.64 percent increase in total indirect tax. $\mathrm{R}$ squared and adjusted $\mathrm{R}$ squared both are 0.99 showing that 99 percent change in total indirect tax is explained by the change in GDP. F and $t$ are values permitting statistically significant fit of the model at 1 percent. DW test is found at 1.40, implies that there is no auto correlation in the model. Among individual tax heads under indirect tax categories, sales tax/VAT has an elasticity coefficient of 0.69 showing that 100 percent increase in GDP has contributed to a 69 percent increase in sales tax/VAT collection. Adjusted R squared is 0.97 showing that 97 percent change in sales tax/VAT is explained by the change in GDP. DW statistics is found at 0.94 , implies that there is positive auto correlation among the disturbance terms. Custom duties have an elasticity coefficient of 0.69 showing that 1 percent increase in GDP has contributed on an average a 0.69 percent increase in custom duties. The model is of good fit at 1 percent significance level. DW test is 1.64. Excise duties, which have the least elasticity coefficient among individual indirect tax categories, are found to be 0.42 showing that 1 percent increase in GDP has contributed on an average a 0.42 percent increase in excise duties collection during the second period of analysis. The variations are best explained thus - the value of adjusted $\mathrm{R}$ squared shows that 97 percent change in excise duties is explained by the change in GDP. $\mathrm{F}$ and $\mathrm{T}$ statistics permit the best theoretical fit of the estimated parameter at 1 percent significance level. DW statistics is found 1.99, showing no auto correlation among errors.

Table 2. Buoyancy Coefficient $\left(\beta_{1}\right)$ for Study Period.

\begin{tabular}{lcccccc}
\hline Tax Heads & Coefficients $\left(\boldsymbol{\beta}_{\mathbf{1}}\right)$ & $\mathbf{R}^{2}$ & Adj. $\mathbf{R}^{2}$ & $\mathbf{T}$ & $\mathbf{F}$ & DW \\
\hline Total Revenue & $1.24(0.034)^{*}$ & 0.99 & 0.99 & 36.42 & 4195.67 & 1.53 \\
Total Tax Revenue & $1.31(0.051)^{*}$ & 0.99 & 0.99 & 25.65 & 3216.09 & 1.60 \\
Non-Tax Revenue & $1.02(0.055)^{*}$ & 0.96 & 0.96 & 18.39 & 493.15 & 1.70 \\
Direct Tax & $1.40(0.080)^{*}$ & 0.98 & 0.98 & 17.49 & 1156.86 & 1.65 \\
Indirect Tax & $1.28(0.043)^{*}$ & 0.99 & 0.99 & 29.96 & 2696.23 & 1.75 \\
Income Tax & $1.70(0.150)^{*}$ & 0.94 & 0.93 & 11.36 & 268.70 & 1.48 \\
Sales Tax/VAT & $1.41(0.049)^{*}$ & 0.99 & 0.98 & 29.17 & 1794.59 & 1.76 \\
Custom Duties & $1.06(0.054)^{*}$ & 0.98 & 0.98 & 19.51 & 951.78 & 1.49 \\
Excise Duties & $1.41(0.110)^{*}$ & 0.96 & 0.95 & 12.70 & 399.85 & 1.88 \\
\hline
\end{tabular}

(Authors own calculate based on Economic survey data and budget Speech).

Note: *values with in parenthesis are the standard errors of the parameters.

During the study period total revenue has a buoyancy coefficient of 1.24 , referring to the fact that every one percent increase in GDP is associated with 1.24 percent increase in total revenue of the country. The model is highly significant, which is supported by high value of $\mathrm{R}$ squared, adjusted $\mathrm{R}$ squared, $\mathrm{F}$ and $\mathrm{t}$ statistics and DW statistic is found to be 1.53 ,implies that there is no auto correlation in the model. Among its components, total tax revenue and total non-tax revenue have buoyancy coefficients of 1.31 and 1.02 respectively. This shows that total tax revenue is found to be more 
buoyant than total non-tax revenue. Both these estimated parameters follow well theoretical fit at 1 percent significance level. At the same time, high values of $\mathrm{R}$ squared and adjusted $\mathrm{R}$ squared support the strong explanatory power of GDP to the changes in revenue collection of the country. DW statistics are found 1.60 and 1.70 for tax and non tax revenue respectively.

Total direct tax has a buoyancy coefficient (1.40) greater than one, showing a relatively buoyant direct tax with respect to GDP. Total indirect tax has a quite lower buoyancy coefficient (1.28) in comparison to total direct tax. This shows that total direct tax seems more responsive than total indirect tax during the study period. The buoyancy coefficient of income tax is found to have greater than unity 1.70 referring that one percent increase in GDP has contributed on an average 1.70 percent increase in income tax during the period. This relationship is best explained at 1 percent significance level. DW statistics is found at 1.48 , implies that there is no auto correlation in the model. Among indirect tax categories, sales tax/VAT has buoyancy coefficient (1.585) followed by custom duties (1.06) and excise duties (1.41). All these models are highly significant at 1 percent which is supported by high value of $\mathrm{R}$ and adjusted $\mathrm{R}$ squared, as well as $\mathrm{F}$ and $\mathrm{T}$ statistics. DW statistics shows that there is no auto correlation among the error terms.

\section{Conclusion and Recommendations}

Nepal is one of the least develop countries. Nepalese economy is suffering from less effective, effortless and over ambition plans, programs and policies. The Government needs huge amount revenue to achieve maximum objective of nation. Lack of sufficient financial resource is the main constraint for the economic development of Nepal. Nepal has been facing the serious problem of resource gap and higher dependency on foreign loan. Resource gap has been increasing at a faster rate than the increase in revenue. Grants and loan as well domestic borrowing are not considered as the permanent solution to fulfill the gap. In our total revenue structure, the share of non-tax revenue is very low as compare to tax revenue. The share of non-tax revenue is not increase in short run. Hence, tax is the best solution to bridge up the resource gap and improvement in tax structure is need.

The most of the elasticity of different tax heads were less than unity for the period from 1990/91 to 2013/14. This is indicative of poor responsiveness and productivity of tax yield with respect to GDP. The elasticity of taxes is very low to compare their respective buoyancy, which indicates some revenue growth seems possible only through discretionary change.

The analysis of structure, productivity and responsiveness of Nepalese tax system also shows that one of the most significant tax reform measure adopted by Government of Nepal is the implementation of broad-base VAT in fiscal year 1997 and it is quite satisfactory performance. However, this improvement is not at all substantial enough to address the issue of increasing fiscal imbalance in the country. As a whole, the above analysis shows deficiency in every aspect of Nepalese tax system such as tax efforts and taxable capacity, structure of individual taxes and their base, administrative feasibility, equity, sustainability and tax payer's compliance and so on. As a result the elasticity of taxes is very low both individually and collectively compared to their respective buoyancy, indicating that some revenue growth seems possible only through discretionary changes. Thus, high buoyancy but low elasticity indicates that discretionary changes are higher than automatic growth. Therefore, an attempt should be made to increase automatic response of taxation and broaden the tax base. Government effort should be made towards increasing every sector to the economy under tax net as much as possible.

NUTA JOURNAL, 5 (1\&2), 2074 : ISSN: 2616 - 017x 


\section{References}

Adhikari, R.P. (1995). Tax Elasticity and Buoyancy in Nepal, Economic Review Vol.8, Nepal Rastra Bank, Kathmandu.

CBS. (2011). Preliminary Report of the Population Census 2011, Central Bureau of Statistics, National Planning Commission, Government of Nepal

Dahal, M. K. (1983). Taxation in Nepal: A study of its Structure, Productivity and Burden, Ph. D. Dissertation of University of Bombay, India.

Dahal, M. K. (2000). Measuring the Responsiveness and Productivity of Tax Yields: A Survey of the Contemporary Approaches, Economic Journal of Department Issue, Department of Economics, Patan Multiple Campus, vol.1 No. 2, Lalitpur, Nepal.

Dahal, M. K. (2009). Taxation in Nepal: Structure, Issue and Reforms, The Economic Journal of Nepal, Vol.32, No.1, Jan-March 2009, Issue No. 125, Kathmandu.

Giri, K. (2013). Measuring Productivity and Responsiveness of Tax Yields in Nepal, Unpublished MPhil. Dissertation, CCEDECON, TU, Kathmandu.

Goode, R. (1984). Government Finance in Developing Countries, Tata Grow Hill, New Delhi, India.

Gujarati, D. N. (2006). Basic Econometrics, Tata McGraw-Hill Publishing Company Limited, New Delhi.

MOF. (2014). Economic Survey 2014. Ministry of Finance, Government of Nepal.

Rana, A. S. (2008). An Analysis of Tax Structure and Responsiveness of Tax Yields in Nepal, Unpublished Ph.D. Dissertation, CCEDECON, TU, Kathmandu.

Sahota, G. S. (1961). Indian Tax Structure and Economic Development, Asia Publishing House, New Delhi, India. 